\title{
THE EFFECTIVENESS OF SCAMPER'S STRATEGY FOR DEVELOPING CREATIVE THINKING IN THE SUBJECT OF HARMONY FOR MUSIC EDUCATION STUDENTS
}

\author{
Jacqueline Jamal SIDHOM ${ }^{1}$, Mahmoud Ahmed AL-WAKEEL ${ }^{2, *}$ \\ ${ }^{1}$ Department of Authorship and Sketchiest, Quantity of Specific Education, Tanta University, Egypt \\ ${ }^{2}$ Music Education Department, Faculty of Specific Education, Tanta University, Egypt
}

\begin{abstract}
There is no doubt that the strength and effectiveness of nations is measured by their creative, active minds capable of adapting and interacting with the challenges of the age and cognitive acceleration to benefit from it and contribute to its development, and this does not come only through minds capable of creative thinking, and therefore researchers were interested in the topic of creativity and defined: understandable, its stages His mental abilities, methods and strategies for training and development, and measures that measure it. Creativity is an integral part of all branches of music, as the musical scientist Berliner pointed out that creativity in music is "composing in real time" and "making an immediate decision in applying and changing musical materials and producing new ideas." Gordon (2001) emphasized the importance of creativity. Musician Whereas, "Teaching a music without creativity is a denial of the essence of music."

Keywords

Effectiveness, Scamper's Strategy, Developing, Creative, Thinking, Harmony, Music Education.
\end{abstract}

\section{Introduction:}

The National Association for Music Education (NAfME) emphasized that through the sciences of music education (listening and tasting, solfege, harmony, rhythm) students should be provided with opportunities to develop creativity.

The National Association of Schools of Music (NASM) affirmed that one of the accreditation criteria for musical education colleges and obtaining a bachelor's degree is "the application of creative thinking through improvisation, composition, and harmonic courses, and hearing and playing instrument training. Using creative thinking does not require a specific teaching material, and accredited colleges must include instructions for teaching creative thinking during the semester.

The College Music Society of the United States of America (2014) prepared a report entitled "Transforming the Study of Music from Its Institutions: An Account of the Gradual Change in Undergraduate Students' Preparation for Music". The report focused on the areas of creativity, diversity and integration in music education, and these three main pillars were described to ensure the suitability of musical education curricula at the university level. "And that the ability to creativity and improvisation is one of the basic skills necessary for the teacher of music education for the twenty-first century, and that many education students Musicals graduated

*Corresponding author: dean_spedu@sed.tanta.edu.eg 
without the ability to create and improvisation, and instead of adding new courses to accreditation requirements for colleges, applications of creative thinking can be integrated into current courses (improvisation, harmony, theories and authorship)

Several researchers point to the importance of creative thinking and improvisation in musical education. Creative thinking and improvisation are an essential part of all aspects of music education and musical styles in different cultures. Several studies have proven the effectiveness of creative thinking for students in the basic education stages (primary, intermediate and secondary).

Many studies dealt with the development of musical creative thinking among the undergraduate student (Khalil, 19, Muhammad, 2009; Muharram, 2009, Heiba, 2008; Al-Shawadafi, 2012). Several researchers have examined how creativity in music can be incorporated into the fields of improvisation; 1997, Nolan, 1995; Rooke) and authorship.

- The use of technology to help teach creativity

What may help persuade musical educators of the value of including creative activities in classroom planning is that creative activities allow students to build their own musical concepts through a process of proper exploration of musical sounds, change in the use of musical elements, and the creation of musical compositions as an integral part of learning. Meaningful musician essential for developing musical understanding.

Harmony is one of the basic subjects in musical studies, and its study is very necessary for any musician, whether a performer (player, singer), composer, or orchestral conductor, as it is a major factor in the perception and understanding of the musical language in general and the field of composition, distribution and musical analysis in particular. Putting the harmonic twists to the melody and accompanying it with the chords and linking them with each other through their sequence depends on the extent of the musician's ability to visualize the sounds of the damaged ones acoustically and imagine their effect on the harmonic distribution, and this is supposed to be acquired through studying the harmony. Harmony is one of the materials that helps to develop the ability to create musical creativity through immediate reading of musical exercises and reformulating them as musical sentences through the harmonic rules that were studied in the course.

The definitions of harmony have varied, and in the New Grove Dictionary, harmony is defined as "the method of collecting notes at a time, forming defects that have a relationship with another group formed in the same way. These successive discrepancies are related to certain relationships between each other within a specific Tonali center."

Studies have revealed many problems in studying Harmony: 
First: The teaching methods used in teaching the subject (the traditional method, which does not suit the nature of the subject with its theoretical and practical aspects, and which needs interactive teaching methods to help students connect between theoretical aspects and their applications on the piano and to treat these problems, the studies used strategies to improve achievement and develop students' ability to creativity.

Second: The difficulty of combining the skills required by Applied Harmony and their understanding of the cognitive aspect of the material and practical applications, as well as the speed of illusion reading, and playing the piano at the same time, which shows the discrepancy between students 'abilities. To address these problems, the study used Therese's strategy to improve achievement and develop students' creativity.

The Harmony course requires the realization of the mind and thinking about applying the rules and punctuations in solving the harmonic exercises (applied, theoretically), which leads to the development of creative thinking and helps the student to replace solutions for Roman numerals and choose the best solutions. Exercises bus or soprano marked and unmarked, which connects the student in the end To create harmonic exercises that contain the characteristics of creative thinking by issuing the largest number of solutions for harmonic exercises (fluency), and that the categories of these solutions vary

For the harmonic exercises (flexibility) until he reaches the authentic composer (Al Asala). Harmony by its nature allows the development of creative thinking when the educational environment and the appropriate environment are provided that provides the opportunity for students to practice creative thinking in harmony (theoretical and practical) and to compose harmonic exercises characterized by novelty and originality, and to reach many solutions for different harmonic exercises. From this standpoint, educators began to investigate the effectiveness of teaching methods that help to implement creative thinking among learners in various school subjects, including harmony, and to gain them skills, experiences, and positive attitudes towards teamwork or creativity.

De Mille, author of a 1997 book entitled "Put your mother on the ceiling" aimed at developing students' imagination. Williams and his colleagues presented 190 a set of methods aimed at stimulating creative expression in students. These methods were based on two main dimensions, cognitive processes (originality, flexibility, fluency, and a tendency to detail), and emotional or affective processes (curiosity, and willingness to deal with risks. And a preference for complexity, and intuition). Then Bob Eberle (18) blended all those previous experiences together to build the SCAMPER program and added them to Williams' methods so that he had a SCAMPER model for developing creative thinking, and he formulated games 
and activities according to the de Mille style in developing the creative imagination. He has (the scientific model, the practical method, and the activities), so that all of this forms a threedimensional cube component to stimulate ideas in a creative manner that combines branching and synthesis thinking, used to generate and develop ideas, and to develop the imagination. The idea is to be worked out in the future, and thus it is a tool for developing and enriching thinking.

SCAMPER means starting, running, jogging, or running away, but the word took a place in the educational field to become a way to develop creative thinking skills, and its letters combined to add the meaning of escaping from the rigid thinking that many people stand up to and contradict with a narrow idea, and creativity in this The word is that it came out of its linguistic meaning so that each letter constitutes a sign of ten implications for my thinking performance. Rashton defines it as a strategy that helps students ask a set of questions about an object or idea by using brainstorming to develop ideas or objects or to confront and solve problems.

Numerous studies have proven the effectiveness of Scamper's strategy in developing achievement, brain skills and innovative thinking in many subjects.

The SCAMPER theory and the questions it contains can develop creative thinking and students' skills in Hamoni by training them in creative thinking and better use of theoretical rules and harmonic exercises to help them combine the skills of initial reading, quick thinking, creativity and playing at the same time.

\section{Research problem:}

Based on the results of the questionnaire, which showed a decline in students 'application of creative thinking skills, and the results of studies that showed many of the students' problems in the subject of harmony. Although many studies have proven the effectiveness of SCAMPER's strategy in developing creative thinking in many academic subjects, - within the limits of the researchers 'knowledge - there is no study that has studied the effectiveness of SCAMPER's strategy for developing students' creative thinking in Harmony. The problem appears clearly in the necessity to design a program to improve academic achievement and develop creative thinking for music education students in the subject matter of harmony.

- The theoretical framework: the concept of creativity Many researchers have tried to define the concept of creativity on the basis that it is: the personality traits of creators, a creative product and the characteristics of that product, a creative process. First: Creativity as personality traits The proponents of this trend see that creative people are distinguished by a number of personality traits. This is what Torrance stresses of the importance of studying the personality traits of creative individuals, which helps to know 
individuals who have the aptitude for creativity in order to help them translate those preparations into actual creative performance. From researchers, they found a number of personality traits of musically creators, distinguished by their strength of intuition, fluency of expression, imagination, sensitivity to movement, rhythm and organization, enabling them to integrate thinking and feelings and express them in the highest degree possible. This musical creativity may appear in the field of musical composition or musical performance in general Second: creative thinking as a product:

Creative thinking as a product is one of the most important aspects through which creativity has been studied. It is observable and more evident because it represents the physical or tangible aspect of creativity.

Wilson asserts that the product of creative thinking must be characterized by:

Novelty: An innovative product is characterized by novelty in light of social and psychological factors. Usefulness: an innovative product helps solve a problem or meet specific needs.

Aesthetic value: it is intended that the creative product enjoys an aesthetic aspect.

Creative product takes many forms:

Mental creativity that is reflected in the form of creative ideas, theories, art, music, story or poem. Practical creativity: which is represented in quantitative forms such as mathematical expansion or reaching a new equation or record in a specific game.

Qualitative creativity: which is the application of a new or effective management of a talent.

In Music Education, David Elliott (190) described the creative product as: a set of creative musical concepts in which students participate through a set of actions such as composition or improvisation that reach the final product. This product is not considered creative unless there is a significant level of quality (Elliott, 1995), and Gordon (2009) explained that the degree of creativity in a musical product depends directly on the musical vocabulary that a person possesses from melody, harmonic and rhythm (2007, Gordon). Morin (2009) asserted that in order for students to display the creative product, they must have basic musical knowledge of melody, harmony and rhythm, and musical creativity is taught by expanding students' musical knowledge.

Third: creative thinking as a process:

Many models explain the creative process, the most important of which is the acceptance of the Wallas model of the stages of the creative process, which is the basis for most programs that train creative thinking in our time. As he indicates that the creative process passes through a number of stages:

Preparation Stage: 
This stage requires identifying the problem or situation that the individual is dealing with, gathering all necessary information about this situation, and trying to examine the information, organize it, and build conclusions about the situation.

The incubation stage:

It is a stage represented by anxiety, fear and hesitation towards the situation and the individual's ability to solve or overcome the problem, and the individual may at this stage divert his attention from the situation, such as performing an activity completely outside of the situation, such as swimming, running, or eating to allow the information to latency and stability.

- Persistence Stage:

Where creativity requires a high degree of persistence to move forward in solving the problem and reaching creative solutions.

Illumination Stage:

It describes the moment when the solution to the problem suddenly arises, describing a state of cognitive integration between the elements of the situation and achieving a holistic, holistic understanding with a high degree of creativity, and this stage is accompanied by the individual's feeling of satisfaction and comfort over his creative respect, while some may feel a bit of astonishment and surprise.

- Verification Stage: The proposed solution must be verified and verified in an organized scientific way to ensure that the conditions and characteristics of the creative solution are met.

- Creative thinking skills

Most researchers and scholars agree that creative thinking includes three main skills, namely fluency, flexibility and originality that are included in the Torrance Test of Creative Thinking, in addition to two sub-skills, sensitivity to problems and details.

- Fluency: it means generating new solutions, coming up with alternatives, and remembering previous information. It also means the ability to produce a large number of good and correct ideas for an issue or problem. Fluency refers to the ability to use a stock of knowledge when needed, so it represents the quantitative aspect of creativity.

Fluency has three types:

Verbal fluency: It is the ability to produce several words beginning with a specific letter.

Intellectual Fluency (Meanings): The ability to generate multiple ideas related to a specific situation.

Fluency of shapes: the ability to quickly engineer a specific shape. Flexibility: it means generating unexpected and varied ideas and shifting from one type of thought to another when responding to a stimulus that challenges the individual's thinking, that is, it is the ability to 
change the individual's cognitive state by changing the situation or its characteristics. Flexibility has two forms: Automatic flexibility: moving from an idea To another quickly and easily. Adaptive flexibility: successful behavior by changing to confront a problem.

- Originality: means the ability to express unique expression through the production of distant ideas more than common and familiar ones. Originality is distinguished by its ability to uniqueness and distinction.

- Sensitivity: means the ability to discover problems and difficulties and discover a lack of information before reaching a solution. . Elaboration: represents the ability of the individual to add new details to the ideas and positions available to him.

- Musical creative thinking skills: - Musical fluency: the ability to produce the largest amount of specific vocal, rhythmic or kinesthetic responses. Musical flexibility: the ability to generate different classes of responses to a specific musical stimulus. Musical originality: the ability to generate new and uncommon responses to a musical stimulus, and to perceive the relationships between musical stimuli.

research results:

1- The first question of the research was: What is the effectiveness of Scamper's strategy in the acquisition of musical education students of the cognitive aspect of the harmonic subject? To answer this question, it became clear from the research results of the first and fourth hypotheses that there is a statistically significant difference between the mean scores of the experimental group students in the pre and post application of the cognitive achievement test - in favor of the post application, and there is a statistically significant difference between the mean scores of the experimental and control groups in the post application. Cognitive achievement test - for the benefit of the experimental group. The results also indicated that the Scamper strategy has a great influence and effectiveness on the development of cognitive achievement in the subject of harmony, and this result may be attributed to: The use of the Scamper strategy in teaching harmony provides students with a classroom environment that depends on the learner's positivity and activity through brainstorming the questions used (replacement, adaptation, Modification, deletion), and applying the rules to find solutions to the hormonal exercises, which helped to increase the achievement of the students of the study group. . Increase students' motivation, excitement and excitement towards learning, as Skamber's strategy provides for conveying ideas and information in a more creative way. . The strategy helped to stimulate the students' previous experiences, especially that cognitive achievement in the subject of harmony requires the integration of previous experiences (the curriculum of the second and third classes that students have in solving the harmonic exercises. The activities included in the strategy 
provided the opportunity for all students to participate at different levels of thought in the different solutions to the exercises. Harmonism, which enhanced their self-confidence. Learning is done cooperatively between students and they build on each other's ideas, which facilitated the process of producing new harmonic exercises. Using Scamper's strategy questions (replacement, adaptation, adjustment, deletion) helped to develop higher mental skills (application, analysis Harmony, evaluation, synthesis) related to the nature of the substance, which is used in the solution of hormonal exercises, thus it is evident from the results of the effectiveness of Scamper's strategy on developing cognitive achievement in the subject of harmony, and this result is consistent with studies (Hani, 2012, Ramadan, 2014, Saleh, 2010) that showed Its results are that the use of the Scamper strategy improves students 'academic achievement in many subjects. Thus, the two researchers have answered the first question: And to verify the effectiveness of Scamper's strategy in the acquisition of music education students of the cognitive aspect of Harmony.

2- The second question for the research was: What is the effectiveness of Scamper's strategy in the acquisition of musical education students of the skill side of the hormonal subject? To answer this question, it became clear from the results of the second and fifth hypotheses that there is a statistically significant difference between the mean scores of the experimental group students in the pre and post applications of the scorecard related to the practical harmony skills - in favor of the post application. There is also a statistically significant difference between the mean scores of the experimental and control groups in the post application of the skill performance observation card of the Harmony subject - in favor of the experimental group. Also, the Scamper strategy has a great impact and effectiveness on developing practical skills of Harmony, and this result may be attributed to: Through exercises on the questions of the Scamper strategy in practical harmony, the skills of problem-solving and immediate performance improve, as the frequent training and diversification in the harmonic exercises increases the skill of the student, both in The preserved part is because it repeats the exercise more than once with the required adjustments (rhythm variations, inventing jumps) or in the initial reading. The difference appears clear between the results of the experimental and control group in practical skills, because teaching in the traditional way does not allow students the opportunity to apply theoretical rules in practical exercises and to master the skills required in practical harmony adequately. Scamper's strategic questions helped to stimulate the students' previous experiences that were studied in the practical harmony curriculum in the previous academic years (second and third year), reaching solutions for practical harmonic exercises that require merging the previous experiences that students have, and integrating and 
synthesizing ideas in a new way. The activities included in the Scamper strategy allowed all students of the experimental group (at different levels of thinking) to participate in generating ideas and solutions for hormonal exercises, which strengthened their self-confidence. The results show the effectiveness of Scamper's strategy in developing practical skills of Harmony. These results are consistent with the results of the study (Ramadan, 2013), which proved the effectiveness of Scamper's strategy for developing problem-solving skills, and (Abdul Qadir and Ismail, 2010, Abu Saif, 2012), which proved the effectiveness of Scamper. In developing writing skills. Thus, the two researchers have answered the second question and verified the effectiveness of Scamper's strategy in the acquisition of musical education students of the skillful side of the Harmony subject.

3- The third question for the research was: What is the effectiveness of Scamper's strategy in developing the creative thinking of music education students in the subject of harmony? To answer this question, it became clear from the results of the third and sixth hypothesis that there is a statistically significant difference between the mean scores of the experimental group students in the pre and post application to test the musical creativity of the subject Harmony in favor of the post application. In addition, there is a statistically significant difference between the mean scores of the experimental and control groups in the post application of the musical creativity test of Harmony - for the benefit of the experimental group. Also, Scamper's strategy has a great influence and effectiveness on the development of musical creativity in the subject of harmony, and this result may be attributed to: The use of Scamper's strategy questions created a suitable environment for practicing creative activities while learning the lessons of harmony. Which increases students' motivation and enthusiasm to learn by brainstorming traditional ideas until we reach creative ideas: through training on the strategy of Scamper and the list of generative questions (replacement, adaptation, modification, deletion) the student replaces Roman numerals exercises marked and unmarked bus in the stairs Adapting the deleted Roman numerals, modifying the harmonic exercises, adding and deleting the tones to change the color of the exercise tones, and training on these questions required in-depth thinking to generate the largest number of ideas and solutions for the harmonic exercises (fluency) that belong to multiple categories (flexibility) and are characterized by novelty (originality) . Scamper's strategic questions helped to stimulate the students' previous experiences that were studied in the Harmony curriculum in the previous academic years (the second and third classes). Reaching creative solutions for harmonic exercises requires merging the previous experiences that students have, and integrating and synthesizing ideas in a new way. Skumber's strategy is based on developing and improving hormonal exercises, and 
coming out of them with a new exercise, through a set of steps to change the training data and reshape relationships. In the theoretical harmony, students develop and improve hormonal exercises until we reach the largest possible number of variations of one exercise, and come up with new exercises. In the practical harmony, students perform the harmonic exercises with different rhythmic variations and the various gestures, until the students reach the production of many different harmonic exercises. - This result is consistent with the results of many studies that have proven the effectiveness of Scamper's strategy in developing creative thinking in many academic subjects (Sabri and Al-Ruwaithi, 2012, Hani, 2012, Ramadan, 2014, Mahmoud, 2012, Saleh, 2012, Al-Thunayan, 2010, 2017, Bakr, 2004; Fahmy \& Qoura, and Hassan, Al-Jabreen, 2017). Thus, the two researchers have answered the third question and verified the effectiveness of Scamper's strategy in developing the creative thinking of music education students in the subject of harmony.

4- The fourth question of the research was: What is the correlation between students 'scores in the achievement test, their scores on the observation card of skill performance, and their scores in the creativity test in the Harmonian subject? To answer this question, it became clear from the results of the seventh hypothesis that there is a positive significant correlation between the scores of the experimental group students on the cognitive achievement test and their scores on the skill performance note card and their scores on the musical creativity test for the subject Harmony. The correlational relationship is likely to be deduced from: the answers to the first, second and third questions, the results of which have proven that the strategy scamper has a great influence and effectiveness on the development of the cognitive, skill and creative aspect in the subject matter, which mainly depends on the higher mental skills of application, analysis, structure, which are used in the aspect Cognitive and applied in the skill aspect and mainly used in creative thinking. This result is consistent with the results of many studies that have shown a positive positive correlation relationship between the cognitive side, skill and creative thinking in many academic subjects (Al-Balshwi, 2009, Al-Youssef, 2011, Abu Al-Ala, 2010, Al-Jahmi, 2014, Al-Oweidi, 2014, Bugs, 2009 ).

Study recommendations:

In light of the findings of the research, the two researchers recommend the following:

\section{Recommendations:}

1- Study the effect of using the Scamper strategy on other variables such as reflective thinking skills, analytical thinking and divergent thinking.

2- The necessity of including teacher preparation programs on the Scamper strategy and how to design music education lessons in light of it. 
3- Holding training courses, seminars and workshops for music education students to introduce the Scamper strategy, and its importance in improving academic achievement, scientific skills and creative thinking.

4- Searching for teaching methods compatible with the nature of Harmony.

5- Studying the effect of using the Scamper strategy on developing creative thinking skills in other musical courses.

\section{References:}

1- Ibrahim, Magdy Aziz. (2008). Creative teaching and teaching thinking. Cairo: The World of Books.

2- Ibn Manzur, Abi al-Fadl Jamal al-Din Muhammad. (2008). Lisan Al Arab, vol. (2), Beirut, Dar Sader.

3- Abu Hatab, Fuad Abd al-Latif (2011). Mental Abilities, i (6), Cairo, The Anglo-Egyptian Library.

4- Abu Saif, Alaa Muhammad. (2012). The effect of Scamper's strategy on improving the creative writing skills of tenth grade female students in Jordan. The Islamic University Journal of Educational and Psychological Studies, 20 (2), 989-304.

5- Al-Badareen, Shady Khaled. (2008). The effectiveness of the idea generation strategy (SCAMBER) in developing the creativity and self-concept of a Jordanian sample of students with learning difficulties, an unpublished master's thesis). Amman Arab University for Graduate Studies, Jordan.

6- Al-Balushi, Suleiman bin Muhammad bin Suleiman. (2008). The relationship between each of the creative thinking abilities, science processes, and academic achievement in different school subjects for a sample of female learners with good and weak achievement in the ninth grade in the Sultanate of Oman. The Educational Journal, Kuwait University, Academic Publication Council, 21 (2), 12-7.

7- Al-Husseini, Abdel Nasser Al-Ashaal. (2008). Developing creative thinking capabilities using the SCAMPER program (unpublished master thesis). Arabian Gulf University, Bahrain. 8- Al Thanayan, Hind bint Abdullah. (2010). The effectiveness of a training program based on Scamper's strategies in improving the skills of generating ideas in written expression among students of Princess Noura Bint Abdul Rahman University in Riyadh. Journal of Educational and Psychological Sciences, Bahrain 19 (1), 9-4.

9- Jabreen, Munira. (2012). The Effectiveness of Using the ScsMPER Strategy to Teach the Jurisprudence Course in the Development of Higher Thinking Skills for Sixth Grade Students in the Primary School in Riyadh, Culture and Development, Egypt, 11 (12), 18-20. 
10- Al-Jahmi, Al-Safi Yusef. (2012). The Effectiveness of Using Electronic Mind Maps in the Development of Creative Thinking and Academic Achievement among Second Grade Industrial Secondary Students, Journal of the Faculty of Education, Assiut University, 2 (4), $300-2$.

11- Al-Oweidi, Nahed Adel. (2012). The effectiveness of a proposed program in light of TRIZ's theory for the development of creative thinking and achievement in geography for first-grade intermediate students in Jeddah. Arab Studies in Education and Psychology, Arab Educators Association, 45 (2), 21-24.

12- Al-Sorour, Nadia. (2008). Introduction to creativity. Amman: Wael House for Printing and Publishing.

13- Al-Shami, Jamal al-Din. (2001). Teacher and student innovation, series of educational psychology books. Alexandria: Dar Al-Wafaa for the World of Printing and Publishing.

14 - Al-Shawadafi, Reham Mahmoud. (2012). The use of some active learning strategies to develop creativity and musical skills of the student teacher, Faculty of Specific Education, unpublished $\mathrm{PhD}$ thesis, College of Education, Zagazig University.

15- Shawan, dear. (12). The Encyclopedia of the Musician (Concise Encyclopedia), the initial printer. Cairo: House of Culture.

16- Al-Sheikhly, Abdul Qadir. (2001). Development of creative thinking. Ammaan Jordan.

17- Al-Youssef Yahya Abd Al-Khaleq. (2011). The Effectiveness of Using the Sundry Synthesis Strategy to Teach the Interpretation Course in the Development of Creative Thinking Skills for First Year Secondary Students in Tabuk Region, Journal of the Faculty of Education in Fayoum, 10, 12-18.

18- Bishara, conciliator. (2008). The Effect of a Training Program for High-Rank Thinking Skills on the Development of Critical and Creative Thinking among Basic Tenth Grade Students, Unpublished PhD Thesis, Yarmouk University, Jordan.

19- Bugs, Najat bint Abdullah. (2008). The effect of enrichment activities - to develop creativity - on the decision-making process and the achievement of female students in the course on educational techniques, studies in curricula and teaching methods, the Egyptian Association for Curricula and Teaching Methods, 19, 2-21.

20- Bayoumi, Ahmed. (12). Cairo Music Dictionary: Ministry of Culture, National Cultural Center, Cairo Opera House.

21- Gray, Fathy. (2008). Teaching thinking concepts and applications. Amman: Dar Al-Fikr for Publishing and Distribution. ) Hegazy, Hisham Ahmed. (2008). The Effect of Using Computers in Teaching Harmony on Musical Achievement and Creativity by Dacy Musical, 
Unpublished PhD Thesis, Faculty of Specific Education, Cairo University.

22- Khalil, Amal Hussein. (12). The effectiveness of a proposed program to develop the performance of music education students in the Faculties of Specific Education in light of the concept of creativity. Unpublished $\mathrm{PhD}$ thesis, Faculty of Education, Menoufia University.

23- Khalil, Amal Hussein. (2008). Creativity and teaching strategies for music education. Alexandria: Scientific Culture House.

24- Get closer. (2010). The problems facing students of the Department of Musical Arts, College of Fine Arts, in the subject of harmony (phonemic compatibility). Journal of the College of Basic Education, ${ }^{9}$, $44-949$ r.

25- Ramadan, life. (2014). The effect of Scamper's strategy on developing achievement, problem-solving skills, and some habits of mind in science for elementary school students. Arab Studies in Education and Psychology, Saudi Arabia, 21, 9-11.

26- Saadeh, Jawdat Ahmed. (2010). Methods of teaching gifted and talented students, Ta. Amman: Orient House for Publishing and Distribution.

27- Sadiq, Amal, Abu Hatab, Fouad. (1994). The Effect of Music on the Development of the Individual Behavior, Research and Studies in Music Psychology and Music Education, The Anglo-Egyptian Library, Cairo.

28- Saleh, Muhammad. (2010). The effectiveness of Scamper's strategy for science education in developing some scientific habits of mind and decision-making skills among middle school students. Journal of the College of Education in Benha, Egypt, 109 (2), 12-18.

29- Sabri, Maher Ismail, and Al-Ruwaithi, Maryam. (2012). The effectiveness of the SCAMBER education strategy in science education in developing innovative thinking skills among gifted students in elementary school in Madinah. Arab Studies in Education and Psychology, 2 (1), 11-42.

30- Abd al-Qadir, Abd al-Raziq, and Ismail, Abd al-Rahim. (2010). The Effectiveness of Scamper's Model in the Development of Creative Linguistic Performance among Linguistically Gifted Students in Preparatory Stage, International Journal of Educational Research, United Arab Emirates University, (2), 9-309.

31- Abdul Karim, Awatif. (No date). Practical Harmony, Part 1.

32- Abd al-Muttalib, Muhammad. (2008). In Deposit Psychology: Theoretical Frameworks and Strategies for Jordan's Development, Amman: Dar Al-Fikr.

33- Atoum, Adnan. (2008). Cognitive Psychology. Amman: Maisarah House for Publishing and Distribution.

34- Ali, Abrar. (2012). The use of Therese theory to develop innovative thinking in teaching 
applied harmony to students of the Faculty of Specific Education. The third and first international scientific conference: developing quality education in light of environmental studies, Faculty of Specific Education, Ain Shams University, Egypt, ґ, ११^ - 74.

35- Corporal, Rabab. (2014). The effectiveness of training based on the use of the five-year learning cycle in developing some creative and musical skills of the student teacher at the Faculty of Specific Education (unpublished Master Thesis), Faculty of Education, Zagazig University.

36- Farag, princess. (12). The effect of teaching solfege and ear education in a certain way on students' comprehension of harmony, music analysis, unpublished master's thesis, Faculty of Music Education, Helwan University.

37- Farag, his princess. (12). Physical rhythm exercises and their role in developing attention for students of the College of Music Education. The first scientific conference, Cairo.

38- Muharram, congratulations. (2008). Adopting some methods of developing innovative thinking to improve the performance of the student teacher in the field education subject, a suggested method, Journal of Music Sciences and Arts, Volume Four

39- Muhammad, Sonia Sameh. (2008). A proposed program to achieve innovation in composing Arabic music for students of the bachelor's stage at the Faculty of Specific Education (unpublished $\mathrm{PhD}$ thesis, Faculty of Specific Education, Cairo University.

40- Mahmoud, Amal. (2010). The effectiveness of science teaching using the strategy of generating ideas (SCAMBER) in developing imaginative thinking skills and some habits of mind among first-grade middle school students. Journal of Scientific Education, Egypt, 19 (2), $1-20$.

41- Excellent, Fatima. (12). The effect of good training in practical harmony on improving performance in theoretical harmony (unpublished master's thesis), Faculty of Music Education, Helwan University.

42- Hani, Mervat Hamed Muhammad. (2012). The effectiveness of the Scamper strategy in developing achievement and generative thinking skills in science among fourth grade students. Educational and social studies, 19 (2), 3-7.

43- Prestige, Saadia Ramadan. (2008). A proposed program for developing the creative thinking of the music education teacher through Arabic melodies to promote free school activity (unpublished PhD thesis), Faculty of Music Education, Helwan University.

44- Azzara, C. D. (1993). Audiation-based improvisation techniques and elementary students' music achievement. Journal of Research in Music Education, 41(4), 328-342.

45- Bamberger, J. (1999). Learning from the children we teach. Bulletin of the Council for 
Research in MusicEducation, 142, 48-74.

46- Bakr, S. M. (2004). The efficacy of somg proposed activities for devoping creative thinking of English learners at the preparatory stage (second year) Unpublished doctoral dissertation, Faculty of Education, University of Cairo, Egypt.

47- Beegle, A. C. (2010). A classroom-based study of small-group planned improvisation with fifth grade children. Journal of Research in Music Education, 58 (3), 219-239. doi: $10.1177 / 0022429410379916$.

48- Berliner, P. F. (1994). Thinking in jazz. Chicago: The University of Chicago Press.

49- Bloom, E. (1954). Grove's dictionary of music and musician. Vol (II), New York: Martin's press.

50- Bitz, M. (1998). Teaching improvisation outside of jazz settings: musical genres that lend themselves to improvisations by beginning student musicians include bluegrass, blues, ska, reggae, rap, klezmer, and rock. Music Educators Journal, 84 (4), 21-41.

51- Brophy, T. S. (2005). A longitudinal study of selected characteristics of children's melodic improvisations. Journal of Research in Music Education, 53 (2), 120-133.

52- Byrne, C. (2002). A spider's web of intrigue. In L. R. Bartel (Ed.), Creativity and Music Education (pp. 195 205). Toronto, ON: Britannia Printers.

53- College Music Society. (2014, November). Transforming music study from its foundations: A manifesto for progressive change in the undergraduate preparation of music majors. Retrieved from https://www.music.org/index/php?option=com_content\&view=article\&id=1859: transforming-musicstudy-from-its-foundations-a-manifesto-for-progressive-change-intheundergrdaute-preparation-of music-majors \&catid=139\&Itemid=101.

54- Collins, D. (2005). A synthesis process model of creative thinking in music composition. Psychology in Music, 33 (2), 193-216.

55- Davidson, L. (1990). Tools and environments for musical creativity. Music Educators Journal, 76, 47-51.

56- Demonline, K. (1999). Educational applications of Band-in-a-Box (as accompaniment, as creative tool, and as aid for teaching styles of music. Canadian Music Educator, 41, 29-30.

57- Douglas, K. A. (2005). The effects of a Music Learning Theory-based pattern instruction curriculum on the improvisational ability of middle school instrumental students. (Master's thesis). Michigan State University.

58- Dunbar-Hall, P. (1999). Composition as the site of music teaching: Pre-service students attitudes to teaching through creative activities. Australian Journal of Music Education, 1, 44- 
62.

59- Eberle, B. (1997). Scamper on: more creative games for imagination development.waco. Tx: Prufrock Press.

60- Eberle, B. (2008).SCAMPER, creative games and activities (let your imagination run wild), waco, TX: prufrack press.

61- Elliott, D. (1995). Music matters: a new philosophy of music education. New York: Oxford University Press.

62- Fahmy, G, A., Qoura, A., \&m Hassan, S. (2017). Using SCAMPER-based activities in teaching story to enhance EFL primary stage pupils' speaking skills (An Exploratory Study). Journal of Research in Curriculum, Instruction and Educational Technology, 3(4), 11-33.

63- Fratia, M. A. (2002). The creative link: an introduction to jazz improvisation. Canadian Music Educator, 43, 16-17.

64- Guilbault, D. M. (2004). The effect of harmonic accompaniment on the tonal achievement and tonal improvisations of children in kindergarten and first grade. Journal of Research in Music Education, 52 (1), 64-76.

65- Guilbault, D. M. (2009). The effects of harmonic accompaniment on the tonal improvisations of students in first through sixth grade. Journal of Research in Music Education, 57 (2), 81-91.

66- Gordon, E.E. (2001). The stakes are low but the consequences are high. Bulletin of the Council for Research in Music Education, 151, 1-10.

67- Gordon, E. E. (2007). Learning sequences in music: Skill, content, and patterns. Chicago: GIA Publications, Inc.

68- Guilford, J. (1997). Creative talents: Their Nature Uses and Development. New York: Bearly limited.

69- Hindemith, P. (1968). A Concentrated Course in Traditional Harmony: Book 1, Part 1With Emphasis on Exercises and a Minimum of Rules, revised edition New York: Schott Music.

70- Hickey, M. (1997). Teaching ensembles to compose and improvise (practical ideas). Music Educators Journal, 83, 17-21.

71- Hickey, M. (1997). Understanding children's musical creative thinking process through qualitative analysis of their MIDI data. Bulletin of the Council for Research in Music Education, 131, 29-30.

72- Howell, S. \& Murphy, K. (1993). Proceedings, the 68th Annual Meeting: Meeting of Region Three - Creative and critical thinking: can music technology assist both? National 
Association of Schools of Music, 81, 103-112.

73- Kanellopoulos, P. A. (1999). Children's conception and practice of musical improvisation. Psychology of Music, 27. 175-191. doi:10.1177/0305735699272008.

74- Kiehn, M. T. (2003). Development of music creativity among elementary school students. Journal of Research in Music Education, 51, (4), 278-288. doi: 10.2307/3345655.

75- Kratus, J. (1990). Structuring the music curriculum for creative learning. Music Educators Journal, 76, 33.

76- Koozin, T. (2018). Common chord Modulation, Retived from, http://tmmtheory.com/study-guide/part-ii unit-2/.

77- Levi, R. (1991). Investigating the creative process: The role of regular musical composition experiences for the elementary child. Journal of Creative Behavior, 25(2), 123-136.

78- McPherson, G. E. (1997). Cognitive strategies and skill acquisition in musical performance. Bulletin of the Council for Research in Music Education, 133, 64-71.

79- Menard, E. (2013). Creative thinking in music: Developing a model for meaningful learning in middle school general music, Music Educators Journal, 100 (2), 61-67.

80- Miller, B. A. (2004). Designing compositional tasks for elementary music classrooms. Research Studies in Music Education, 22, 59-71.

81- Moore, J. L. (1990). Strategies for fostering creative thinking. Music Educators Journal, $76,38-42$.

82- Morin, F. (2002). Finding the music within: An instructional model for composing with children. In L. R. Bartel (Ed.), Creativity and Music Education (pp. 152- 178). Toronto, ON: Britannia Printers.

83- National Association of Schools of Music Handbook. (2010-2011). www.nasm.art.org.

84- Nolan, E. (1995). Focus on improvisation: Music Content Standard 3; orchestra - drawing creativity out of your students. Teaching Music, 2:5, 28-29.

85- Priest, T.L. (1997). Fostering creative and critical thinking in a beginning instrumental music class (Doctoral dissertation). University of Illinois at Urbana-Champaign.

86- Priest, T. (2002). Creative thinking in instrumental classes. Music Educators Journal, 88, (4) $47-58$.

87- Pike, J. (2000). Sampling music technology (creativity and electro-acoustic composition). Music Teacher, 79, 35.

88- Reese, S. (2001). Tools for thinking in sound: technology tools for composing and improvising are revolutionizing teaching methods that encourage creativity in sound among students of all ages. Music Educators Journal, 88, 42-26. 
89- Reimer, B. (2003). A Philosophy of Music Education (3rd ed.). Englewood Cliffs, New Jersey: Prentice Hall, Inc.

90- Reynolds, N. (2002). Computers, creativity and composition in the primary school: an analysis of two compositions. Australian Journal of Music Education, 1, 16-26.

91- Rooke, M. (1990). Technique and creativity, par 4: to coin a phrase (improvisation and composition as aids). Music Teacher, 69, 14-15.

92- Runco, M. \&, Albert, R. (1990). The Theories of Creativity. Bufflo. 50. Rushton, C. (2006). The invention convention in the classroom: the basics of disciplined creative thinking, for every grade level, Worthington. $\mathrm{OH}$ : Just Thinking publishers.

93- Sadie, S. (2001). The New Grove Dictionary of Music and Musicians. 2nd ed. New York: Grove.

94- Schopp, S. E. (2006). A study of the effects of National Standards for Music Education, number 3, improvisation and number 4, composition on high school band instruction in New York State (Doctoral dissertation). Teachers College, Columbia University.

95- Stauffer, S. L. (2001). Composing with computers: Meg makes music. Bulletin for the Council for Research in Music Education, 150, 1-20.

96- Stauffer, S. L. (2002). Connections between the musical and life experiences of young composers and their compositions. Journal of Research in Music Education, 50, 301-322.

97- Sullivan, T. (2002). Creativity in action. In L. R. Bartel (Ed.), Creativity and Music Education (pp. 179 194). Toronto, ON: Britannia Printers.

98- Torrance, E. P. (1974). The Torrance Tests of Creative Thinking: Norms-Technical Manual. Research Edition. Verbal Tests, Forms A and B. Figural Tests, Forms A and B. Princeton, NJ: Personnel Press .

99- Warrack, J. \&, West, E. (1996). The concise oxford dictionary of opera. New York: Oxford University Press.

100- Wiggins, J. (1999). Teacher control and creativity (carefully designed compositional experiences can foster students creative processes and augment teachers' assessment efforts. Music Educators Journal, 85, 30:35.

101- William Drab kin. (2007). "Neapolitan sixth chord". In L. Root, Deane. Grove Music Online. Oxford Music Online. Oxford University Press.

102- Jehan Farouk ABU AL-KHAIR, STUDY THE EFFECTIVENESS OF THE ART OF IMPLEMENTING AN EXTENSION PROGRAM ON THE FEASIBILITY STUDY ON THE DIRECTION OF UNIVERSITY STUDENTS KING ABDUL AZIZ TOWARDS SMALL PROJECTS, International Journal of Education and Learning Research, Vol. 2, No. 1, 2019, 
Jacqueline Jamal SIDHOM and Mahmoud Ahmed AL-WAKEEL

pp. 20-26.

Received: June 18, 2019

Accepted: August 28, 2019 